\title{
Genomic Diversity of Hepatitis B Virus Infection Associated With Fulminant Hepatitis B Development
}

\author{
Thomas Mina ${ }^{1}$; Samad Amini-Bavil-Olyaee ${ }^{2}$; Frank Tacke ${ }^{3}$; Piet Maes ${ }^{1}$; Marc Van Ranst ${ }^{1}$; \\ Mahmoud Reza Pourkarim ${ }^{1,44^{*}}$ \\ ${ }^{1}$ Department of Microbiology and Immunology, Laboratory of Clinical and Epidemiological Virology, Rega Institute for Medical Research, KU Leuven, Leuven, Belgium \\ ${ }^{2}$ Department of Molecular Microbiology and Immunology, Harlyne J. Norris Cancer Research Tower, Keck School of Medicine, University of Southern California, Los Angeles, CA, USA \\ 3 Department of Medicine III, RWTH-University Hospital Aachen, Aachen, Germany \\ 4 Blood Transfusion Research Centre, High Institute for Research and Education in Transfusion Medicine, Tehran, IR Iran \\ ${ }^{*}$ Corresponding Author: Mahmoud Reza Pourkarim, Department of Microbiology and Immunology, Laboratory of Clinical and Epidemiological Virology, Rega Institute for Medical \\ Research, KU Leuven, P. O. Box: BE-3000, Leuven, Belgium. Tel: +32-16332145, Fax: +32-16332141, E-mail: mahmoudreza.pourkarim@uzleuven.be
}

Received: April 23, 2015; Accepted: May 25, 2015

Context: After five decades of Hepatitis B Virus (HBV) vaccine discovery, HBV is still a major public health problem. Due to the high genetic diversity of HBV and selective pressure of the host immune system, intra-host evolution of this virus in different clinical manifestations is a hot topic of research. HBV infection causes a range of clinical manifestations from acute to chronic infection, cirrhosis and hepatocellular carcinoma. Among all forms of HBV infection manifestations, fulminant hepatitis B infection possesses the highest fatality rate. Almost 1\% of the acutely infected patients develop fulminant hepatitis B, in which the mortality rate is around $70 \%$.

Evidence Acquisition: All published papers deposited in Genbank, on the topic of fulminant hepatitis were reviewed and their virological aspects were investigated. In this review, we highlight the genomic diversity of HBV reported from patients with fulminant HBV infection. Results: The most commonly detected diversities affect regulatory motifs of $\mathrm{HBV}$ in the core and $\mathrm{S}$ region, indicating that these alterations may convert the virus to an aggressive strain. Moreover, mutations at T-cell and B-cell epitopes located in pre-S1 and pre-S2 proteins may lead to an immune evasion of the virus, likely favoring a more severe clinical course of infection. Furthermore, point and frame shift mutations in the core region increase the viral replication of $\mathrm{HBV}$ and help virus to evade from immune system and guarantee its persistence.

Conclusions: Fulminant hepatitis B is associated with distinct mutational patterns of HBV, underlining that genomic diversity of the virus is an important factor determining its pathogenicity.

Keywords: Hepatitis B Virus; Liver Failure, Acute; Human Genome Project

\section{Context}

\subsection{Fulminant Hepatitis}

Fulminant hepatitis, also known as Fulminant Hepatic Failure (FHF), is a critical illness with a high mortality rate, reaching up to $80 \%$ (1). It is a rare condition, in which rapid destruction of the liver parenchyma leads to coagulopathy, altered mental status and subsequently multiorgan failure in an otherwise healthy individual (2). Owing to the advances in the field of liver transplantation, antiviral therapy and critical care management, survival rates have been substantially improved to more than $65 \%$ (3).

Over the years, there have been several different definitions of fulminant hepatitis or acute liver failure. The most widely accepted definition is proposed by the American Association for the Study of Liver Diseases (AASLD), which includes evidence of coagulopathy (International Normalization Ratio [INR] $\geq 1.5$ ) and presence of encephalopathy in a patient without pre-existing cirrhosis and with an illness of less than 26 weeks duration (2). In 1968, Trey and
Davidson first introduced the term FHF to describe the onset of altered mental status within eight weeks of initial symptoms with no pre-existing liver disease (4). Two decades later, Bernuau et al. suggested that the term FHF would describe cases where encephalopathy developed within two weeks of the onset of jaundice and that subfulminant hepatic failure, cases where encephalopathy developed between 2 weeks and 3 months after the onset of jaundice (5). The acute liver failure (ALF) term was proposed by O'Grady et al. who further classified liver failure into three groups of (i) hyper-acute (onset within 1 week), (ii) acute (onset between 8 and 28 days) and (iii) sub-acute (onset between 29 days and 12 weeks). The latter classification was established based on the survival rate of the groups (6). Still, this classification is no more valid since a recent study has shown no prognostic significance distinct from the cause of the illness (3). In addition, patients in whom hepatic encephalopathy appeared between 8 and 24 weeks after the first symptoms are classified as having Late-Onset Hepatic Failure (LOHF) (7).

Some of the apparent factors that cause FHF are drug

Copyright (C) 2015, Kowsar Corp. This is an open-access article distributed under the terms of the Creative Commons Attribution-NonCommercial 4.0 International License (http://creativecommons.org/licenses/by-nc/4.0/) which permits copy and redistribute the material just in noncommercial usages, provided the original work is properly cited. 
induced liver injury, viral hepatitis, autoimmune liver disease and liver shock, whilst many FHF cases have no definable cause (3). In the present review, we assessed FHF caused by hepatitis B virus (HBV) infection, referred as fulminant hepatitis B (FHB).

\subsection{Fulminant Hepatitis $B(F H B)$ Infection}

HBV infection leads to a wide spectrum of liver diseases, spanning from acute to chronic hepatitis, cirrhosis and Hepatocellular Carcinoma (HCC) (8). Only 1\% of acutely infected patients develop fulminant hepatitis, which has a mortality rate of around $70 \%(9)$. Although there are few reports on the role of other hepatotropic viruses, $\mathrm{HBV}$ is probably the most common viral cause of FHF in most regions of the world (10). In developing countries, fulminant viral hepatitis, and particularly acute HBV infection, is the predominant cause of FHF. On the contrary, acetaminophen or other drug-induced hepatoxicity is the most frequent cause of ALF in western countries $(11,12)$.

Acute exacerbation of chronic HBV infection can be also classified as a form of FHF. This acute deterioration can be related to precipitating events, such as chemotherapy or immunosuppressive agents, which can induce severe flares of hepatitis and lead to fatal fulminant hepatitis. To prevent HBV reactivation in inactive carriers, guidelines strongly suggest strict follow-up and careful monitoring before and during immunosuppressive therapy (13). FHF in the setting of HBV reactivation has a much higher morbidity and mortality rate than de novo fulminant hepatitis (14). In addition, Hepatitis D Virus (HDV) superinfection of a chronic HBV patient can also result in FHF (15). As soon as an individual shows signs of coagulopathy, jaundice or encephalopathy, he or she should be hospitalized and transferred to a Liver Transplantation (LT) center. Furthermore, antiviral therapy should be administered to the patient to prevent the recurrence of HBV after transplantation and then treatment has to be continued indefinitely (11). Deterioration of liver function in a patient with HBV-related liver cirrhosis belongs to a different disease entity, which is nowadays classified as "Acute-on-Chronic Liver Failure" (ACLF) (16).

\subsection{HBV Genome Organization}

$\mathrm{HBV}$ is a DNA virus with a genome length of only $3.2 \mathrm{~kb}(17)$. Its genome is a partly double-stranded circular DNA organized into four overlapping Open Reading Frames (ORF) including $S$ for the surface gene, $C$ for the core gene, $P$ for the polymerase gene and $\mathrm{X}$ for the $\mathrm{X}$ gene. The $\mathrm{S}$ ORF encodes three envelope proteins, the large, medium and small (HBsAg), which are synthesized by starting transcription with pre-S1, pre-S2 or S gene, respectively. The C ORF encodes two proteins, "e" antigen (HBeAg) and core antigen ( $\mathrm{HBCAg}$ ) transcribed from precore (PC) RNA and pregenomic RNA, respectively. Production of both PC and pregenomic RNA is controlled by Basal Core Promoter (BCP) elements. HBeAg is a non-structural protein, which is secreted by infected he- patocytes and serves as a marker of active replication and as an immune modulator. HBcAg is the nucleocapsid that encloses the viral DNA together with the polymerase. The X protein acts as a transactivator on HBV enhancer assisting virus replication $(18,19)$. The DNA molecule of HBV consists of a complete strand (L or minus), which is covalently attached to viral polymerase at the 5'-end and of an incomplete strand (S or plus), about two-thirds complete (19).

\section{Evidence Acquisition}

\subsection{HBV Genome Diversity and its Sources}

HBV DNA replicates via the Reverse Transcriptase (RT) enzyme, which lacks proofreading activity. Due to the error-prone nature of the RT enzyme, HBV has a relatively high substitution rate compared to other DNA viruses. The average daily production rate of $\mathrm{HBV}$ is up to $10^{11}$ virions per day, with an estimated error rate of $1.4-3.2 \times 10^{-5}$ nucleotide substitutions per site per year. Therefore, HBV exists as a quasispecies population, in which eventually a predominant strain is selected by endogenous (host immune system) and exogenous factors (antiviral therapy and vaccination). Likewise, many variations can be detected on nucleotide as well as on protein level across HBV genome $(20,21)$. The resulted HBV variants seem to contribute to viral pathogenic persistence and therapeutic limitations like antiviral treatment and vaccination (22). Because of this heterogeneity, HBV has a genetic classification, in which different HBV genotypes, subgenotypes and subtype (serotype) have been defined $(23,24)$.

\subsection{HBV Classification}

Human HBV is the prototype member of Hepadnaviridae, which include two recognized genera, the Orthohepadnavirus and the Avihepadnavirus (25). Phylogenetic analysis has classified HBV into eight genotypes (A - H), defined by an intergroup nucleotide divergence greater than $7.5 \%$ over the complete genome sequence (26). In addition, multiple subgenotypes have been recognized within genotypes (almost 40 subgenotypes), with more than $4 \%$ and less than $7.5 \%$ divergence over the full-length genome $(19,27)$. HBV "clades" are used as a subdivision within subgenotypes, presenting less than $4 \%$ nucleotide diversity over the complete genome sequences $(23,26)$. Due to several insertions and deletions among the genome, HBV genotypes have different genomic lengths (28).

HBV genotypes have a distinctive geographical distribution around the world (24). For example, genotype A is prevalent in northwestern Europe, USA and Africa. Genotypes B and C are restricted in Asia; genotype D predominates in the Mediterranean area, but is also found worldwide. Genotype E is prevalent in the African continent, genotype $\mathrm{F}$ in Latin America and genotype $\mathrm{H}$ in the indigenous population of Central America (29). The very rare reported genotype $G$ has been recently found all around the world (19). 
Mina T et al.

Prior to molecular classification, HBV strains were classified into four major HBsAg subtypes (serotypes) based on immunological heterogeneity of HBsAg (30). This subtype grouping is based on different HBsAg epitopes, present on the Major Hydrophilic Region (MHR), which spans between amino acid residues 99 - 169 (31). This part possesses a major immunogenic region called " $a$ " determinant domain (amino acid 124 - 147) (19). The four main serotypes are $a d w$, ayw, adr and ayr (32). A correlation between HBV subtypes and certain genotypes has been observed (33). In addition, genotype and serotype association often displays a characteristic geographical distribution $(18,34)$.

\subsection{HBV Genotypes and Disease Progression}

Recent studies suggested an association of different HBV (sub) genotypes with the clinical course of hepatitis. For instance, virus strains of subgenotype A2 have been frequently detected in acute forms of HBV infection (35). Other reports have shown that acute HBV infection with genotype A may increase the risk of progression to chronic hepatitis compared to other genotypes (36). Moreover, patients infected with genotype $C$ have a greater frequency and severity of liver dysfunction compared to genotype B (27). It has been reported that subgenotype C2 increases the risk of HCC development compared to $\mathrm{C} 1$ (37). In general, genotypes $\mathrm{C}$ and $\mathrm{D}$ are found to be more often associated to liver cirrhosis and HCC than genotypes A and B (38). Among the genotype B infections, subgenotype B6 strains are commonly related with a mild clinical outcome, while B1 strains lead more often to acute and fulminant hepatitis B (39). Another interesting aspect is that patients infected with genotype F show lower survival rates than those infected with genotype A or D (40). In addition, genotype $\mathrm{F}$ infections detected in the Amazonian basin are associated with fulminant hepatitis in the context of HDV co-infection (41). Likewise, in the USA, genotype D infection has been identified as an independent risk factor for fulminant hepatitis (42).

Interestingly, a significant number of patients infected with genotype A or D were found to be anti-HBe antibody positive, while those infected with genotype D showed higher levels of serum Alanine Transaminase (ALT) (43). In addition, genotype $\mathrm{D}$ has been frequently reported among inactive carriers of HBsAg (44). Patients infected with genotypes A and B have reported to show a higher HBeAg seroconversion rate and normalization of serum ALT levels after interferon-alpha treatment than those infected with genotype C or D (45). Likewise, following pegylated interferon-alpha treatment, only genotypes $A$ and $B$ responded with $\mathrm{HBeAg}$ seroconversion and substantial decrease in HBsAg serum titers, while in patients with genotypes C and D, no change was observed (46). Moreover, it has been observed that patients infected with genotype A can develop an antiviral resistance earlier than genotype D. In a similar way, it has been re- ported that genotype B strains are more likely to develop resistance against lamivudine antiviral than genotype $C$ strains (27).

\section{Results}

\subsection{Genome Diversities Related to Clinical Outcome}

Most naturally occurring mutations on HBV genome are located at the C ORF. The dual BCP mutation A1762T + G1764A results in a down regulation of HBeAg synthesis, and the PC G1896A stop-codon mutation prevents the expression of HBeAg. Another PC mutation A1899G has been reported in combination with G1896A, which stabilizes the lower stem of the " $\varepsilon$ " encapsidation signal and enhances the replication. The presence of both BCP and PC variants has been reported in severe liver cirrhosis and HCC. Several mutations, including deletions and insertions or stop codons have been reported in the S ORF of the HBV genome (47). Deletions or missense mutations in the Pre-S2 region can abolish the synthesis of the protein and alter B and T cell epitopes $(19,48)$. Moreover, HBsAg insertion or deletion or missense mutations can help the virus to evade host immune response (19). Truncated HBV surface proteins can contribute to the chronicity of HBV infections (49). Furthermore, a pattern of hotspot mutations located at the $\mathrm{X}$ region of the HBV genome (xI127T, xK130M, xV131I and xF132Y) are also known to be associated with transactivating function and HCC development (50).

\subsection{HBV Genome Variations Related to Fulminant Hepatitis B Infection}

It has been hypothesized that both viral and host factors play a role in the pathogenesis and clinical outcome of HBV infection and that FHF develops when there is an overwhelming immune-mediated lysis of infected hepatocytes (51). It has been suggested that FHB can be explained by three main virologic markers as (i) an increase in viral replication fitness, (ii) a change in viral gene expression and/or (iii) an alteration of $\mathrm{B}$ and $\mathrm{T}$ cell epitopes (52). These factors are discussed below in detail and summarized in Table 1.

\subsection{1. (i) Pre-S and S Gene Variations Associated to FHB}

During the course of fulminant hepatitis infection, several in vitro studies have isolated certain HBV variants with Pre-S/S gene mutations. A study on FHB strains identified a hepatitis B immune globulin (HBIG)-escape mutant sG145R on the HBsAg, being responsible for about $30 \%$ inhibition of virion secretion and increased replication compared to wild type strains (53). In addition, mutations in CAAT element of the $\mathrm{S}$ promoter have shown to cause a reduction in the $S$ protein level and intracellular viral retention (54). Many other vaccine and/or HBIG escape mutations, as well as insertions in the " $a$ " determi- 
nant of the HBsAg, have been detected to cause a defect in viral particle secretion and an alteration of host immune system epitopes $(53,55)$. Moreover, an association between pre-S mutants and fulminant hepatitis has been reported. It is hypothesized that since $B$ and $T$ cell epitopes located on both pre-S1 and pre-S2 proteins, this may lead to an immune evasion of the virus and a more severe infection $(56,57)$. Of note, mutations along the pre-S/S gene may induce retention of the surface proteins in the Endoplasmic Reticulum (ER) of the hepatocytes, resulting in an ER stress that may induce oxidative DNA damage and genomic instability (58).

\subsection{2. (ii) BCP, Precore and Core Gene Variations Associ- ated to $\mathrm{FHB}$}

Many evidences suggest that FHB is strongly associated with HBV strains that do not produce HBeAg due to either BCP or PC mutations. During a study, HBV DNA clones were propagated from FHB patients and sequenced within the $\mathrm{BCP}$ and $\mathrm{PC}$ region. Interestingly, a significant number of clones carried the PC G1896A stop-codon and G1899A mutations as well as the dual BCP A1762T + G1764A mutation (59). The precursor protein of HBeAg decreases the encapsidation of the pregenomic RNA. Therefore, an absence or decrease of HBeAg synthesis can lead to enhanced viral replication and consequently increased host immune response (60). Investigators have shown that the double A1762T + G1764A mutation can slightly increase viral DNA replication, while the C1766T + T1768A mutational pattern exhibits a 10 -fold higher replication capacity than a wild type strain (61). Importantly, in vitro experiments indicate that mutations can synergistically influence HBV replication. For instance, BCP and PC can further enhance the replication of G145R and other "adeterminant" mutants (62).

Hepatocyte Nuclear transcription Factors (HNF) can regulate the function of HBV promoters and enhancers. They act on nuclear receptor binding sites, which are present in the Enhancer 1 (EN1), Enhancer 2 (EN2) and in the $\mathrm{BCP}$ region of the $\mathrm{HBV}$ genome. Thus, mutations in the enhancer elements and core promoter region can alter the HNF's binding sites or even favor the formation of new binding sites (63). In a Swedish study, both dual BCP mutations, A1762T + G1764A and G1764T + C1766G, were affected by the emergence of another BCP mutation at the position 1757. It has been suggested that both $\mathrm{BCP}$ variants form putative new binding sites Hepatocyte Nuclear Factor 3 and 1 (HNF3 and HNF1), respectively. As a consequence, patients who carried the above core promoter variants had higher viral load and serum aminotransferase levels than patients who did not (64). Similarly, in a case study of HBV reactivation after receiving immunosuppressive therapy, which was conducted in France, an 11-bp insertion (between 1775 - 1776) on the $\mathrm{BCP}$ region has been detected. The insertion has led to the formation of a novel HNF1 binding site and subsequently an enhanced viral replication and fulminant hepatitis (65).

\begin{tabular}{|c|c|c|}
\hline ORF & HBV nt or aa Variation & Effect \\
\hline \multicolumn{3}{|l|}{$\mathbf{C}$} \\
\hline \multirow[t]{8}{*}{$\mathrm{BCP} / \mathrm{PC}$} & $\mathrm{T} 1753 \mathrm{C} / \mathrm{A} / \mathrm{G}, \mathrm{T} 1754 \mathrm{C} / \mathrm{G}$ & decreased HBeAg production, enhanced replication \\
\hline & $\mathrm{A} 1762 \mathrm{~T}+\mathrm{G} 1764 \mathrm{~A}$ & $\begin{array}{l}\text { HNF3 binding site formation, decreased HBeAg production } \\
\text { enhanced replication }\end{array}$ \\
\hline & $\mathrm{G} 1764 \mathrm{~T}+\mathrm{C} 1766 \mathrm{G}$ & HNF1 binding site formation, enhanced replication \\
\hline & $\mathrm{C} 1766 \mathrm{~T}+\mathrm{T} 1768 \mathrm{~A}$ & enhanced replication \\
\hline & 11bp insertion: $1775-1776$ & HNF1 binding site formation, enhanced replication \\
\hline & $\mathrm{T} 1825 \mathrm{C}+\mathrm{A} 1827 \mathrm{C}$ & may affect the HBV life cycle \\
\hline & $\mathrm{G} 1896 \mathrm{~A}+\mathrm{G} 1899 \mathrm{~A}$ & abolished HBeAg expression, enhanced replication \\
\hline & G1862A & decreased HBeAg production enhanced replication \\
\hline \multirow[t]{2}{*}{ Core } & T1961C/A/G C1962D & T cell epitope alteration \\
\hline & A2339G & T cell epitope alteration, enhanced replication \\
\hline $\mathbf{X}$ & xI127T, xK130M xV131I, xF132Y & "hotspot" mutations may enhance or disrupt the replication \\
\hline \multicolumn{3}{|l|}{$\mathbf{S}$} \\
\hline Pre-S1/Pre-S2 & $\begin{array}{l}\text { Pre-S insertion, deletion or missense } \\
\text { mutations }\end{array}$ & $\begin{array}{l}\text { defective Pre-S proteins, T and B cell epitopes alteration, imbalance } \\
\text { of S protein synthesis and intracellular retention, cytotoxicity }\end{array}$ \\
\hline HBsAg & $\begin{array}{l}\text { Immune escape mutations sM125T, sT127P, } \\
\text { sG145R }\end{array}$ & $\begin{array}{c}\text { vaccine and HBIG therapy failure, reduced virion secretion, } \\
\text { enhanced replication }\end{array}$ \\
\hline $\mathbf{P}$ & RT mutations pR/W153Q, pL180M + pM204V & restored HBV replication, LAM resistance \\
\hline
\end{tabular}


Mina T et al.

Other mutations including T1753C/A/G, T1754C/G and G1862A in the BCP and PC have also been reported in FHB infection. It has been speculated that these variants cause fulminant hepatitis by increasing HBV replication and reducing HBeAg production $(66,67)$. An enhancement of HBV replication in parallel with reduced or abrogated HBeAg expression could probably trigger host immune response and lead to extensive hepatic injury, like fulminant hepatitis (68). Two nucleotide substitutions, T1825C and A1827C, situated on a well conserved 11 bp sequence of Direct Repeat-1 (DR1) were also reported to be implicated with FHB. These variants may affect the virus life cycle, since DR1 plays a pivotal role on the HBV replication (56).

Certain mutations in the core gene at nucleotides 1961 and 1962 were found to be associated with fulminant hepatitis as well. These mutations could change the amino acid S21, located in the HLA-A2 restricted Cytotoxic T Lymphocyte (CTL) epitope, spanning from amino acid 18 - 27, and favor the persistence of HBV (39). A mutation A2339G, which corresponds to core protein codon 147 located in the CTL epitopes, could also favor HBV persistence. The A2339G mutation was shown to enhance the replication of $\mathrm{HBV}$ in vitro and being associated with the inhibition of a furin-like protease. This results in a higher expression of complete core protein, which could function as a trans-acting regulator of HBV replication (69).

\subsection{3. (iii) Pol Gene Variations Associated to FHB}

The HBV genome is organized in a way that the envelope (S) gene is completely overlapped by the polymerase $(\mathrm{P})$ gene. Therefore, substitution in the S gene has a corresponding alteration in the polymerase gene and vice versa (19). For instance, the escape mutation sG145R in the HBsAg protein corresponds in a change on the HBV RT region of the polymerase at codon rtR/W153Q. This RT mutation was found to partially restore the in vitro replicative capacity of a lamivudine-resistant rtL180M + M204V HBV strain (70). The emergence of multidrug-resistant HBV has been reported during antiviral therapy alone or in combination with HBIG therapy. These HBV resistant variants may lead to reactivation of the virus in a liver transplant recipient and development of fulminant hepatitis $B$ infection $(71,72)$.

\subsection{4. (iv) X Gene Variations Associated to FHB}

Because of the overlap between HBV X and core region "hotspot" mutations (xI127T, xK130M, xV131I and xF132Y) affecting both proteins could arise. In detail, the mutations T1753C/A/G, A1762T, G1764A, C1766T and T1768A in the $C$ region result in amino acid changes xI127T, XK130M, $\mathrm{xV131I}$ and $\mathrm{xF132Y}$ in the $\mathrm{X}$ protein, respectively (50). Since the $\mathrm{X}$ gene overlaps with the BCP and enhancer II complex, these "hotspot" mutations may enhance or disrupt the replication and expression of HBV and lead to fulminant hepatitis (73).

\subsection{Fulminant Hepatitis B After Immunosuppression}

HBV reactivation or exacerbation related to immunosuppressive therapy is an increasing clinical problem, which requires special attention (74). The recurrence of $\mathrm{HBV}$ infection can be observed in both inactive HBV carriers and occult, which are undergoing immunosuppressive chemotherapy for cancer. With the same manner, immunosuppressive agents given to patients with autoimmune diseases can also increase the risk of HBV reactivation (75). For instance, the anti-inflammatory drugs adalimumab (trade name Humira $($ ) or infliximab (trade name Remicade $®$ ), which bind to tumor necrosis factor- $\alpha$ (TNF- $\alpha$ ), have been approved in the USA by the Food and Drug Administration (FDA) for the treatment of several autoimmune diseases. Since TNF- $\alpha$ is an important pro-inflammatory cytokine of the immune system, adalimumab or infliximab treatment may lead to serious viral infections and reactivations, which can result to life threatening situations like fatal fulminant hepatitis B (76). Immunosuppression may allow the virus to proliferate, which extends to increased HBV DNA levels and HBeAg serum levels. Thus, stopping the therapy with immunosuppressive agents reactivates the host immune system and results in a rapid destruction of the infected hepatocytes. The emergence of anti-TNF- $\alpha$ agents as a key therapeutic option for autoimmune conditions has been associated with increased HBV reactivation cases (77). Based on this observation, current guidelines recommend preemptive therapy of anti-HBc positive individuals to prevent $\mathrm{HBV}$ reactivation as well as continuous antiviral treatment in patients with concomitant chronic HBV infection (78).

\subsection{Fulminant Hepatitis B Treatment Options}

FHB patients require strict virological surveillance to establish an early management of the severe condition and its complexities. As soon as an individual shows signs of coagulopathy, jaundice or encephalopathy, the patient should be managed in an Intensive Care Unit (ICU) and transferred to a Liver Transplantation (LT) center (11). Whether a patient would undergo liver transplantation depends on the probability of spontaneous hepatic recovery, which can be estimated by variables like the degree of encephalopathy, patients age and the cause of fulminant hepatitis (79). While no treatment is indicated for mild acute hepatitis B, there are compelling arguments that antiviral therapy (e.g., with lamivudine, tenofovir or entecavir) should be started in patients with signs of significant liver impairment (e.g., INR > 1.5). For instance, in severe, but non-fulminant hepatitis B, antiviral therapy may significantly accelerate the recovery $(80,81)$. Due to the rarity of fulminant hepatitis B, only limited data exist on the efficacy of antiviral therapy in FHB. Small studies on this condition, mostly conducted with lamivudine, indicated that antiviral therapy can be advantageous at least in a subgroup 
of patients with FHB $(82,83)$. Even though antiviral therapy may not always alter the clinical course and avoid transplantation, it can still reduce the risk of reinfection in case of liver transplantation (84).

Orthotopic Liver Transplantation (OLT) is the only therapeutic option proven to improve the survival rates for patients already in advanced liver failure. During the last decade, OLT has helped to improve the survival rates of FHF patients from $15 \%$ to about 60 - 80\% (3). The clinical outcome as well as the graft survival in HBV LT recipients has been improved. This significant step in LT is particularly an effective strategy of HBIG prophylactic therapy alone or in combination with preoperative antiviral agents followed by indefinite treatment (85). However, the emergence of nucleot (s) ide resistant mutants in the polymerase and HBIG escape mutants in the surface gene can lead to an adverse clinical outcome and a graft failure. Post-OLT follow-up studies have recognized a number of mutations related to HBV relapse and subsequent graft loss, like pI533L on the polymerase due to HBIG therapy and pL533I, pS559T, pM550I amino acid changes due to lamivudine antiviral therapy (71).

\section{Conclusions}

In summary, $\mathrm{HBV}$ infection is considered as one of the main causes of fulminant hepatitis in humans. Clinical manifestations of this severe type of infection are the consequence of interaction between virus and host immune system. In spite of the fact that HBV genotypes and subgenotypes show distinct clinical outcomes, all HBV variants have been reported in FHF context. FHB isolates present particular diversities within hepatitis viral genome, which may enhance viral invasiveness. These variants can lead to an increased HBV replication, altered immune epitopes and modified viral gene expression. Therefore, understanding HBV genomic diversity in FHB patients, will be useful for further studies regarding the management of FHB infections.

\section{Acknowledgements}

Mahmoud Reza Pourkarim received a postdoctoral grant from the "Fonds voor Wetenschappelijk Onderzoek (FWO) Vlaanderen".

\section{Authors' Contributions}

Study design was done by Mahmoud Reza Pourkarim. Thomas Mina wrote the whole review. Virological aspects were edited by Samad Amini Bavil Olyaee and Piet Maes. Clinical parts and general editing were done by Frank Tacke and Marc Van Ranst.

\section{Funding/Support}

Mahmoud Reza Pourkarim is supported by a postdoctoral grant from the 'Fonds voor Wetenschappelijk Onderzoek (FWO) Vlaanderen'.

\section{References}

1. Rakela J, Lange SM, Ludwig J, Baldus WP. Fulminant hepatitis: Mayo Clinic experience with 34 cases. Mayo Clin Proc 1985;60(5):289-92.

2. Polson J, Lee WM, American Association for the Study of Liver D. AASLD position paper: the management of acute liver failure. Hepatology. 2005;41(5):1179-97.

3. Ostapowicz G, Fontana RJ, Schiodt FV, Larson A, Davern TJ, Han $\mathrm{SH}$, et al. Results of a prospective study of acute liver failure at 17 tertiary care centers in the United States. Ann Intern Med. 2002;137(12):947-54.

4. Trey C, Lipworth L, Chalmers TC, Davidson CS, Gottlieb LS, Popper $\mathrm{H}$, et al. Fulminant hepatic failure. Presumable contribution to halothane. NEngl J Med.1968;279(15):798-801.

5. Bernuau J, Goudeau A, Poynard T, Dubois F, Lesage G, Yvonnet $\mathrm{B}$, et al. Multivariate analysis of prognostic factors in fulminant hepatitis B. Hepatology. 1986;6(4):648-51.

6. O'Grady JG, Schalm SW, Williams R. Acute liver failure: redefining the syndromes. Lancet. 1993;342(8866):273-5.

7. Gimson AE, O'Grady J, Ede RJ, Portmann B, Williams R. Late onset hepatic failure: clinical, serological and histological features. Hepatology. 1986;6(2):288-94.

8. Liang TJ. Hepatitis B: the virus and disease. Hepatology. 2009;49(5 Suppl):S13-21.

9. Panassie L, Borentain P, Nafati C, Bernardin G, Doudier B, Thibault $\mathrm{V}$, et al. Fatal fulminant primary hepatitis B virus infections with G1896A precore viral mutants in southeastern France. Clin Res Hepatol Gastroenterol. 2012;36(1):e1-8.

10. O'Grady JG. Acute liver failure. Postgrad Med J. 2005;81(953):148-54.

11. Jayakumar S, Chowdhury R, Ye C, Karvellas CJ. Fulminant viral hepatitis. Crit Care Clin. 2013;29(3):677-97.

12. Hadem J, Tacke F, Bruns T, Langgartner J, Strnad P, Denk GU, et al Etiologies and outcomes of acute liver failure in Germany. Clin Gastroenterol Hepatol. 2012;10(6):664-9 e2.

13. Oketani M, Ido A, Uto H, Tsubouchi H. Prevention of hepatitis $\mathrm{B}$ virus reactivation in patients receiving immunosuppressive therapy or chemotherapy. Hepatol Res. 2012;42(7):627-36.

14. Mindikoglu AL, Regev A, Schiff ER. Hepatitis B virus reactivation after cytotoxic chemotherapy: the disease and its prevention. Clin Gastroenterol Hepatol. 2006;4(9):1076-81.

15. Lee WM. Acute liver failure. N Engl J Med.1993;329(25):1862-72.

16. Moreau R, Jalan R, Gines P, Pavesi M, Angeli P, Cordoba J, et al. Acute-on-chronic liver failure is a distinct syndrome that develops in patients with acute decompensation of cirrhosis. Gastroenterology. 2013;144(7):1426-37.

17. Kao JH, Chen DS. Global control of hepatitis B virus infection. Lancet Infect Dis. 2002;2(7):395-403.

18. Echevarria JM, Avellon A. Hepatitis B virus genetic diversity.J Med Virol. 2006;78 Suppl 1:S36-42.

19. Kay A, Zoulim F. Hepatitis B virus genetic variability and evolution. Virus Res. 2007;127(2):164-76.

20. Chotiyaputta W, Lok AS. Hepatitis B virus variants. Nat Rev Gastroenterol Hepatol. 2009;6(8):453-62.

21. Pourkarim MR, Amini-Bavil-Olyaee S, Verbeeck J, Lemey P, Zeller M, Rahman M, et al. Molecular evolutionary analysis and mutational pattern of full-length genomes of hepatitis B virus isolated from Belgian patients with different clinical manifestations. J Med Virol. 2010;82(3):379-89.

22. Chen L, Zheng CX, Lin MH, Huang ZX, Chen RH, Li QG, et al. Distinct quasispecies characteristics and positive selection within precore/core gene in hepatitis B virus HBV associated acute-onchronic liver failure. J Gastroenterol Hepatol. 2013;28(6):1040-6.

23. Pourkarim MR, Lemey P, Amini-Bavil-Olyaee S, Maes P, Van Ranst M. Novel hepatitis B virus subgenotype A6 in African-Belgian patients. JClin Virol. 2010;47(1):93-6.

24. Pourkarim MR, Amini-Bavil-Olyaee S, Kurbanov F, Van Ranst M, Tacke F. Molecular identification of hepatitis B virus genotypes/ subgenotypes: revised classification hurdles and updated resolutions. World J Gastroenterol. 2014;20(23):7152-68.

25. Zoulim F, Berthillon P, Guerhier FL, Seigneres B, Germon S, Pichoud $\mathrm{C}$, et al. Animal models for the study of HBV infection and 
Mina T et al.

the evaluation of new anti-HBV strategies.J Gastroenterol Hepatol. 2002;17 Suppl:S460-3.

26. Kramvis A, Arakawa K, Yu MC, Nogueira R, Stram DO, Kew MC. Relationship of serological subtype, basic core promoter and precore mutations to genotypes/subgenotypes of hepatitis B virus. Med Virol. 2008;80(1):27-46.

27. Kramvis A, Kew MC. Relationship of genotypes of hepatitis B virus to mutations, disease progression and response to antiviral therapy.J Viral Hepat. 2005;12(5):456-64.

28. Bartholomeusz A, Locarnini SA, Ayres A, Thompson G, Sozzi V, Angus P, et al., editors. Molecular modelling of hepatitis B virus polymerase and adefovir resistance identifies three clusters of mutations.; Hepatology.; 2004; John Wiley \& Sons Inc, 111 River ST, Hoboken, NJ 07030 USA; p. 246A.

29. Norder H, Courouce AM, Coursaget P, Echevarria JM, Lee SD, Mushahwar IK, et al. Genetic diversity of hepatitis B virus strains derived worldwide: genotypes, subgenotypes, and HBsAg subtypes. Intervirology. 2004;47(6):289-309.

30. Okamoto H, Imai M, Tsuda F, Tanaka T, Miyakawa Y, Mayumi M. Point mutation in the $S$ gene of hepatitis B virus for a $\mathrm{d} / \mathrm{y}$ or $\mathrm{w} / \mathrm{r}$ subtypic change in two blood donors carrying a surface antigen of compound subtype adyr or adwr. JVirol.1987;61(10):3030-4.

31. Carman WF. The clinical significance of surface antigen variants of hepatitis B virus. JViral Hepat. 1997;4 Suppl 1:11-20.

32. Peterson DL, Paul DA, Lam J, Tribby ,I, Achord DT. Antigenic structure of hepatitis B surface antigen: identification of the "d" subtype determinant by chemical modification and use of monoclonal antibodies. J Immunol. 1984;132(2):920-7.

33. Pourkarim MR, Sharifi Z, Soleimani A, Amini-Bavil-Olyaee S, Elsadek Fakhr A, Sijmons S, et al. Evolutionary analysis of HBV "S" antigen genetic diversity in Iranian blood donors: a nationwide study. J Med Virol. 2014;86(1):144-55.

34. Pineda-Pena AC, Faria NR, Mina T, Amini-Bavil-Olyaee S, Alavian SM, Lemey P, et al. Epidemiological history and genomic characterization of non-D1 HBV strains identified in Iran.J Clin Virol. 2015;63:38-41.

35. Tamada Y, Yatsuhashi H, Masaki N, Nakamuta M, Mita E, Komatsu T, et al. Hepatitis B virus strains of subgenotype A2 with an identical sequence spreading rapidly from the capital region to all over Japan in patients with acute hepatitis B. Gut. 2012;61(5):765-73.

36. Suzuki Y, Kobayashi M, Ikeda K, Suzuki F, Arfase Y, Akuta N, et al. Persistence of acute infection with hepatitis $B$ virus genotype $A$ and treatment in Japan.J Med Virol. 2005;76(1):33-9.

37. McMahon BJ. The influence of hepatitis B virus genotype and subgenotype on the natural history of chronic hepatitis B. Hepatol Int. 2009;3(2):334-42.

38. Shi YH. Correlation between hepatitis B virus genotypes and clinical outcomes. Jpn J Infect Dis. 2012;65(6):476-82.

39. Inoue J, Ueno Y, Kawamura K, Yamamoto T, Mano Y, Miura M, et al Association between S21 substitution in the core protein of hepatitis B virus and fulminant hepatitis. J Clin Virol. 2012;55(2):147-52.

40. Gomes-Gouvea MS, Soares MC, Bensabath G, de Carvalho-Mello IM, Brito EM, Souza OS, et al. Hepatitis B virus and hepatitis delta virus genotypes in outbreaks of fulminant hepatitis (Labrea black fever) in the western Brazilian Amazon region. J Gen Virol. 2009;90(Pt 11):2638-43.

41. Casey JL, Niro GA, Engle RE, Vega A, Gomez H, McCarthy M, et al. Hepatitis B virus (HBV)/hepatitis D virus (HDV) coinfection in outbreaks of acute hepatitis in the Peruvian Amazon basin: the roles of HDV genotype III and HBV genotype F. J Infect Dis. 1996;174(5):920-6.

42. Wai CT, Fontana RJ, Polson J, Hussain M, Shakil AO, Han SH, et al. Clinical outcome and virological characteristics of hepatitis B-related acute liver failure in the United States. J Viral Hepat. 2005;12(2):192-8.

43. Victoria Fda S, Oliveira CM, Victoria MB, Victoria CB, Ferreira LC. Characterization of HBeAg-negative chronic hepatitis B in western Brazilian Amazonia. Braz J Infect Dis. 2008;12(1):27-37.

44. Baig S, Siddiqui AA, Ahmed W, Qureshi H, Arif A. The association of complex liver disorders with HBV genotypes prevalent in Pakistan. Virol J. 2007;4:128.

45. Erhardt A, Blondin D, Hauck K, Sagir A, Kohnle T, Heintges T, et al.
Response to interferon alfa is hepatitis B virus genotype dependent: genotype A is more sensitive to interferon than genotype D. Gut. 2005;54(7):1009-13.

46. Janssen HL, van Zonneveld M, Senturk H, Zeuzem S, Akarca US Cakaloglu Y, et al. Pegylated interferon alfa-2b alone or in combination with lamivudine for HBeAg-positive chronic hepatitis B:a randomised trial. Lancet. 2005;365(9454):123-9.

47. Pourkarim MR, Lemey P, Amini-Bavil-Olyaee S, Houspie L, Verbeeck J, Rahman M, et al. Molecular characterization of hepatitis B virus strains circulating in Belgian patients co-infected with HIV and HBV: overt and occult infection. J Med Virol.2011;83(11):1876-84.

48. Fernholz D, Galle PR, Stemler M, Brunetto M, Bonino F, Will H Infectious hepatitis B virus variant defective in pre-S2 protein expression in a chronic carrier. Virology. 1993;194(1):137-48.

49. Bartholomeusz A, Locarnini S. Hepatitis B virus mutants and fulminant hepatitis B: fitness plus phenotype. Hepatology. 2001;34(2):432-5

50. Kitab B, Essaid El Feydi A, Afifi R, Trepo C, Benazzouz M, Essamri $\mathrm{W}$, et al. Variability in the precore and core promoter regions of HBV strains in Morocco: characterization and impact on liver disease progression. PLoS One. 2012;7(8):e42891

51. Wright TL, Mamish D, Combs C, Kim M, Donegan E, Ferrell L, et al Hepatitis B virus and apparent fulminant non-A, non-B hepatitis. Lancet. 1992;339(8799):952-5.

52. Sterneck M, Kalinina T, Gunther S, Fischer L, Santantonio T, Greten $\mathrm{H}$, et al. Functional analysis of HBV genomes from patients with fulminant hepatitis. Hepatology. 1998;28(5):1390-7.

53. Kalinina T, Riu A, Fischer L, Will H, Sterneck M. A dominant hepatitis $B$ virus population defective in virus secretion because of several S-gene mutations from a patient with fulminant hepatitis. Hepatology. 2001;34(2):385-94.

54. Bock CT, Tillmann HL, Maschek HJ, Manns MP, Trautwein C. A preS mutation isolated from a patient with chronic hepatitis B infection leads to virus retention and misassembly. Gastroenterology. 1997;113(6):1976-82.

55. Ghany MG, Ayola B, Villamil FG, Gish RG, Rojter S, Vierling JM, et al. Hepatitis B virus $S$ mutants in liver transplant recipients who were reinfected despite hepatitis B immune globulin prophylaxis. Hepatology.1998;27(1):213-22.

56. Bagaglio S, Albarello L, Biswas P, Uberti-Foppa C, Fortis C, Morsica G. Virological pattern of hepatitis B infection in an HIV-positive man with fatal fulminant hepatitis B: a case report. J Med Case Rep. 2009;3:110.

57. Pollicino T, Zanetti AR, Cacciola I, Petit MA, Smedile A, Campo S et al. Pre-S2 defective hepatitis B virus infection in patients with fulminant hepatitis. Hepatology. 1997;26(2):495-9.

58. Pollicino T, Cacciola I, Saffioti F, Raimondo G. Hepatitis B virus PreS/S gene variants: pathobiology and clinical implications. $J$ Hepatol. 2014;61(2):408-17.

59. Sato S, Suzuki K, Akahane Y, Akamatsu K, Akiyama K, Yunomura $\mathrm{K}$, et al. Hepatitis B virus strains with mutations in the core promoter in patients with fulminant hepatitis. Ann Intern Med. 1995;122(4):241-8.

60. Baumert TF, Rogers SA, Hasegawa K, Liang TJ. Two core promotor mutations identified in a hepatitis B virus strain associated with fulminant hepatitis result in enhanced viral replication. J Clin Invest. 1996;98(10):2268-76

61. Parekh S, Zoulim F, Ahn SH, Tsai A, Li J, Kawai S, et al. Genome replication, virion secretion, and e antigen expression of naturally occurring hepatitis B virus core promoter mutants. J Virol. 2003;77(12):6601-12.

62. Amini-Bavil-Olyaee S, Vucur M, Luedde T, Trautwein C, Tacke F. Differential impact of immune escape mutations G145R and P120T on the replication of lamivudine-resistant hepatitis $B$ virus $\mathrm{e}$ antigen-positive and -negative strains. JVirol. 2010;84(2):1026-33.

63. Zheng Y, Li J, Ou JH. Regulation of hepatitis B virus core promoter by transcription factors HNF1 and HNF4 and the viral X protein. $J$ Virol. 2004;78(13):6908-14.

64. Sendi H, Mehrab-Mohseni M, Zali MR, Norder H, Magnius LO. T1764G1766 core promoter double mutants are restricted to Hepatitis B virus strains with an A1757 and are common in genotype D. J Gen Virol. 2005;86(Pt 9):2451-8. 
65. Gerolami R, Henry M, Borentain P, Colson P, Botta D, Tamalet C. Fulminant hepatitis $B$ associated with a specific insertion in the basal core promoter region of hepatitis B virus DNA after immunosuppressive treatment. Clin Infect Dis. 2005;40(4):e24-7.

66. Imamura T, Yokosuka O, Kurihara T, Kanda T, Fukai K, Imazeki F, et al. Distribution of hepatitis B viral genotypes and mutations in the core promoter and precore regions in acute forms of liver disease in patients from Chiba, Japan. Gut. 2003;52(11):1630-7.

67. Hou J, Lin Y, Waters J, Wang Z, Min J, Liao H, et al. Detection and significance of a G1862T variant of hepatitis B virus in Chinese patients with fulminant hepatitis. J Gen Virol. 2002;83(Pt 9):2291-8.

68. Kusakabe A, Tanaka Y, Mochida S, Nakayama N, Inoue K, Sata $\mathrm{M}$, et al. Case-control study for the identification of virological factors associated with fulminant hepatitis B. Hepatol Res. 2009;39(7):648-56

69. Sugiyama M, Tanaka Y, Kurbanov F, Nakayama N, Mochida S, Mizokami M. Influences on hepatitis B virus replication by a naturally occurring mutation in the core gene. Virology. 2007;365(2):285-91.

70. Torresi J, Earnest-Silveira L, Deliyannis G, Edgtton K, Zhuang H, Locarnini SA, et al. Reduced antigenicity of the hepatitis B virus HBsAg protein arising as a consequence of sequence changes in the overlapping polymerase gene that are selected by lamivudine therapy. Virology. 2002;293(2):305-13.

71. de Man RA, Bartholomeusz AI, Niesters HG, Zondervan PE, Locarnini SA. The sequential occurrence of viral mutations in a liver transplant recipient re-infected with hepatitis B: hepatitis B immune globulin escape, famciclovir non-response, followed by lamivudine resistance resulting in graft loss.J Hepatol. 1998;29(4):669-75.

72. Peters MG, Singer G, Howard T, Jacobsmeyer S, Xiong X, Gibbs $\mathrm{CS}$, et al. Fulminant hepatic failure resulting from lamivudineresistant hepatitis $\mathrm{B}$ virus in a renal transplant recipient: durable response after orthotopic liver transplantation on adefovir dipivoxil and hepatitis B immune globulin. Transplantation. 1999;68(12):1912-4.

73. Kaneko M, Uchida T, Moriyama M, Arakawa Y, Shikata T, Gotoh $\mathrm{K}$, et al. Probable implication of mutations of the $\mathrm{X}$ open reading frame in the onset of fulminant hepatitis B. J Med Virol. 1995;47(3):204-8.

74. Jalan R, Gines P, Olson JC, Mookerjee RP, Moreau R, Garcia-Tsao G, et al. Acute-on chronic liver failure. J Hepatol. 2012;57(6):1336-48.

75. Laurenti R, Giovannangeli F, Gubinelli E, Viviano MT, Errico A Leoni L, et al. Long-term safety of anti-TNF adalimumab in $\mathrm{HBC}$ antibody-positive psoriatic arthritis patients: a retrospective case series of 8 patients. Clin Dev Immunol. 2013;2013:410521.

76. Cantini F, Boccia S, Goletti D, Iannone F, Leoncini E, Panic N, et al. HBV Reactivation in Patients Treated with Antitumor Necrosis Factor-Alpha (TNF-alpha) Agents for Rheumatic and Dermatologic Conditions: A Systematic Review and Meta-Analysis. Int $J$ Rheumatol. 2014;2014:926836.

77. Domm S, Cinatl J, Mrowietz U. The impact of treatment with tumour necrosis factor-alpha antagonists on the course of chronic viral infections: a review of the literature. Br J Dermatol. 2008;159(6):1217-28.

78. European Association For The Study Of The L. EASL clinical practice guidelines: Management of chronic hepatitis B virus infection. J Hepatol. 2012;57(1):167-85.

79. O'Grady JG, Alexander GJ, Hayllar KM, Williams R. Early indicators of prognosis in fulminant hepatic failure. Gastroenterology. 1989;97(2):439-45.

80. Wiegand J, Wedemeyer H, Franke A, Rossler S, Zeuzem S, Teuber $\mathrm{G}$, et al. Treatment of severe, nonfulminant acute hepatitis B with lamivudine vs placebo: a prospective randomized double-blinded multicentre trial. J Viral Hepat. 2014;21(10):744-50.

81. Amini-Bavil-Olyaee S, Trautwein C, Tacke F. Relevance of hepatitis $\mathrm{B}$ virus genome variability in organ transplantation. Hepat Mon. 2007;7(1):35-41.

82. Yu JW, Sun LJ, Yan BZ, Kang P, Zhao YH. Lamivudine treatment is associated with improved survival in fulminant hepatitis B. Liver Int. 2011;31(4):499-506.

83. Tillmann HL, Hadem J, Leifeld L, Zachou K, Canbay A, Eisenbach $\mathrm{C}$, et al. Safety and efficacy of lamivudine in patients with severe acute or fulminant hepatitis B, a multicenter experience. J Viral Hepat. 2006;13(4):256-63.

84. Tillmann HL, Patel K. Therapy of acute and fulminant hepatitis B. Intervirology. 2014;57(3-4):181-8.

85. Wu TJ, Chen TC, Wang F, Chan KM, Soong RS, Chou HS, et al. Large fragment pre-S deletion and high viral load independently predict hepatitis B relapse after liver transplantation. PLoS One. 2012;7(2):e32189. 